deficiency. Moreover, since a cobalt supplement did not enhance live-weight gains at the level of food intake of the cobalt-deficient lambs, the increase in live weight that occurred when lambs on an unrestricted cobalt-deficient diet received a cobalt supplement must have been due to an increased consumption of food, that is, to an increase in the appetite of the lambs.

4. The bearing of this finding on the physiological role of cobalt in ruminants is briefly discussed.

\title{
REFERENCES
}

Das, P. K. \& Stewart, J. (I950). Emp. F. exp. Agric. 18, I I2.

Stewart, J. (1946). Scot. Agric. 26, 6.

Stewart, J. (I95I). Brit. F. Nutr. 5, 320.

\section{Autoradiographic Study of Growth and Calcium Metabolism in the Long Bones of the Rat}

\author{
By D. H. TOMLIN \\ Department of Physics, University of Reading \\ AND KATHLEEN M. HENRY AND S. K. KON \\ National Institute for Research in Dairying, University of Reading \\ (Received 20 November 1952)
}

It is well known that skeletal growth is influenced by nutrition, but detailed knowledge of the effects is by no means complete. We are of the opinion that long-term experiments covering an appreciable part of the life span of the experimental animal are best suited for the study of bone growth and development, and we have already published results of metabolic studies carried out under such conditions (Henry \& Kon, I947, I953).

Apart from metabolic tests, use of tracer substances is perhaps the most satisfactory method of studying bone growth in detail. Tracers that have been used in this way fall into two classes: ( $x$ ) organic dyes that, when taken with the food or injected into the circulation, form coloured bone salts and thus label new bone material, and (2) radioactive isotopes of the elements that participate in bone formation. The classic experiments of Hunter (1837) and the work of Brash (1934 $a, b)$ and Payton (1932), in which madder was given to growing pigs, are examples of the first method. Radioactive phosphorus, ${ }^{32} \mathrm{P}$, has been used by many workers in studying various aspects of skeletal metabolism. Autoradiography of bone sections from animals that have received a radioactive tracer reveals the distribution of labelled element in the section. A comprehensive account of this technique, with an extensive bibliography, has been published by Bourne (1952). The autoradiographic technique with ${ }^{32} \mathrm{P}$ has 
been used by Leblond, Wilkinson, Bélanger \& Robichon (1950) to investigate the formation of new bone in the rat.

The usefulness of experiments on bone growth with the isotopes ${ }^{32} \mathrm{P}$ and ${ }^{45} \mathrm{Ca}$ has been often called in question on the ground that the degree of metabolic exchange between these elements in bone tissue and plasma was too great to allow accurate interpretation either of autoradiographs or of radiochemical analysis (see, for example, Neuman \& Riley, I947; Harrison \& Harrison, 1950).

We believe that these conclusions resulted, at least in part, from the experimental methods that have nearly always been adopted in such tracer experiments. Usually a single dose of the tracer has been administered by injection or stomach tube, and the bones have then been examined for radioactivity at various subsequent times. It seems clear that under such conditions the specific activity of the blood $\mathbf{P}$ or $\mathrm{Ca}$ must be continuously changing from the moment of injection and that the labelled material appearing in the bones must accordingly have a wide range of specific activity. This effect would certainly make interpretation of results difficult, particularly in attempting to distinguish between growth and exchange.

In the experiments to be described here, ${ }^{45} \mathrm{Ca}$ (half-life $\mathrm{I} 80$ days) was used as a tracer to study by autoradiography the development of the long bones of the rat over considerable periods. The tracer was given in the food, under physiological conditions, continuously for many weeks, thus providing a nearly constant level of blood $\mathrm{Ca}$ specific activity over a long interval, in comparison with which the 'endeffects' due to the initial rise and final decay of the specific activity would be unimportant. It was thought that this method would allow clear distinction to be made between the specific activities of newly deposited radioactive bone material and of old material that had become labelled by exchange.

Our methods thus parallel those used by Brash (1934a, $b$ ) and Payton (1932), who used madder as a tracer, and it is of interest to inquire if the two techniques lead to similar results. Further experiments are being carried out to examine this question in detail, but general indications of agreement are contained in the present paper. The autoradiographic technique gives the advantage of direct photographic representation of the location of labelled bone and also the possibility of making quantitative measurements, since the optical density in a region of autoradiographic reaction may be related to the specific activity of the corresponding bone material.

The aim of the study was, therefore, to establish the usefulness of the autoradiographic method with ${ }^{45} \mathrm{Ca}$ for investigating bone development under both normal and abnormal dietary circumstances, with special reference to $\mathrm{Ca}$ metabolism. The isotope has characteristics that make it particularly suitable for autoradiography, and these are summarized as follows, comparison being made in particular with ${ }^{32} \mathrm{P}$.

(I) A higher resolution is intrinsically possible because of the low energy of the ${ }^{45} \mathrm{Ca} \beta$-particles. The average range of the particles is about $0.1 \mathrm{~mm}$ in material of unit density compared with about $2.0 \mathrm{~mm}$ for the ${ }^{32} \mathrm{P}$ radiation. It is thus possible to obtain ${ }^{45} \mathrm{Ca}$ autoradiographs from thick specimens with considerably better resolution than with ${ }^{32} \mathrm{P}$, since the effective thickness of the specimen is limited by the $\beta$-particle range. 
(2) ${ }^{45} \mathrm{Ca}$ has a half-life of $\mathrm{I} 80$ days compared with ${ }^{14} \cdot 7$ days for ${ }^{32} \mathrm{P}$, so that ${ }^{45} \mathrm{Ca}$ autoradiographs of bones of rats near the end of their natural life are capable of showing radioactive deposits laid down when the animals were very young.

(3) $\mathrm{Ca}$ is more specifically located in bone than is $\mathrm{P}$.

\section{Rats}

\section{EXPERIMENTAL}

Young hooded Norwegian male rats of our own breeding were used in experiments of which some extended over the major part of the animals' natural life and were planned to show details of the bone-growth mechanism and of the exchange of $\mathrm{Ca}$ in compact bone. The effect of diets differing in $\mathrm{Ca}$ content was also studied.

All the rats were from mothers that had received the stock-colony diet (Folley, Ikin, Kon \& Watson, 1938; Henry \& Kon, 1952) and, before being placed on experiment, the same diet for about I week after weaning.

\section{Diets}

Diets $24 \mathrm{I}$ and 248 of previous experiments (Henry \& Kon, 1953) were again used. The low-Ca diet (diet 24I) contained $0.15 \% \mathrm{Ca}$ and $0.37 \% \mathrm{P}$ and the high-Ca diet (diet 248 ) $0.8 \mathrm{r} \% \mathrm{Ca}$ and $0.83 \% \mathrm{P}$. When radioactive $\mathrm{Ca}$ had to be included it was added to the diet as carbonate at the rate of $50 \mathrm{mg}$ (initially $5 \mu \mathrm{c}$ )/ $/ \mathrm{roo} \mathrm{g}$ diet, so that the young rats consumed about $0.5 \mu \mathrm{c}$ daily. Previous tests had shown that this quantity had no detectable ill effects on the health and growth of rats over a 3 -month period. As the dose was kept constant, the specific activity of the $\mathrm{Ca}$ was higher in the low-Ca diet by a factor of about 5. The radioactive $\mathrm{Ca}$ was prepared by the Atomic Energy Research Establishment, Harwell, by irradiating $\mathrm{CaO}$ in the pile.

\section{Experiment I}

A group of rats was given the radioactive low-Ca diet continuously from the age of 30 days, and subgroups, each containing four animals, denoted by $\mathrm{I} a, \mathrm{I} b, \ldots \mathrm{I} h$, were killed at intervals of approximately 2 weeks. Fig. I shows the treatment in a concise manner.

\section{Experiment 2}

A group of rats was given the radioactive low-Ca diet from the age of 27 days for a period of 80 days, at the end of which one subgroup (identified as subgroup 2a) was killed. The remaining animals were divided into three further subgroups each of four rats $(2 b, 2 c$ and $2 d)$ and received alternately the radioactive and non-radioactive low-Ca diet as shown in Fig. 2. One subgroup was killed at the end of each experimental period at 218 days $(2 b), 30 \mathrm{I}$ days $(2 c)$ and 419 days $(2 d)$. During the second ${ }^{45} \mathrm{Ca}$-feeding period (subgroup $2 c$ ) a fresh batch of ${ }^{45} \mathrm{Ca}$ was used, and the activity of the diet was higher than if the original sample had been used in its original concentration. Thus the newly deposited bone was clearly distinguishable from that formed during the first period. A fifth subgroup (2e) was given ${ }^{45} \mathrm{Ca}$ for the first 80 days of the experiment and killed at 560 days having received no more ${ }^{45} \mathrm{Ca}$. 
A further group was similarly treated, except that the high-Ca diet was given throughout. Again each subgroup contained four animals.

\section{Autoradiographic technique}

Rats were killed by coal-gas, the femora and humeri were removed and, after being cleaned and dried at $105^{\circ}$ for $24 \mathrm{~h}$, were embedded in paraffin wax ${ }^{*}$ and sectioned longitudinally. This was done by cutting bone away from one side with a razor until the marrow cavity was exposed along its entire length, when it was filled with wax. The block was then mounted on a $3 \times \mathrm{I}$ in. microscope slide with beeswax with the cut face uppermost, and the section was completed by successive stages of grinding with carborundum and emery powder. The plane of the final section could be controlled to some extent during the initial grinding, which was carried out on the

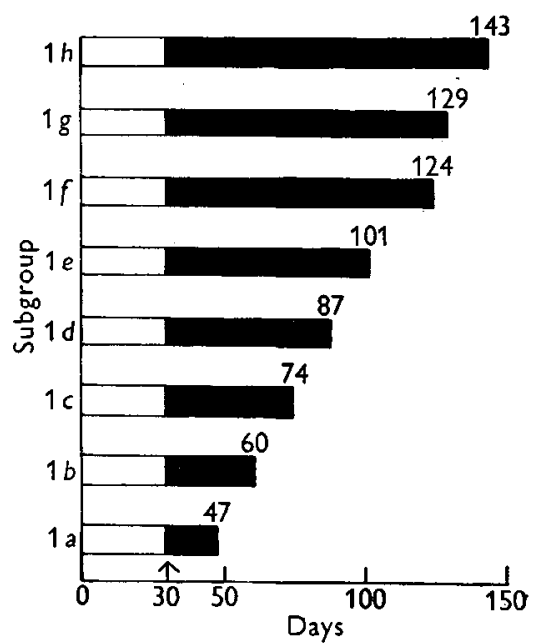

Fig. r. Dietary periods in Exp. r.

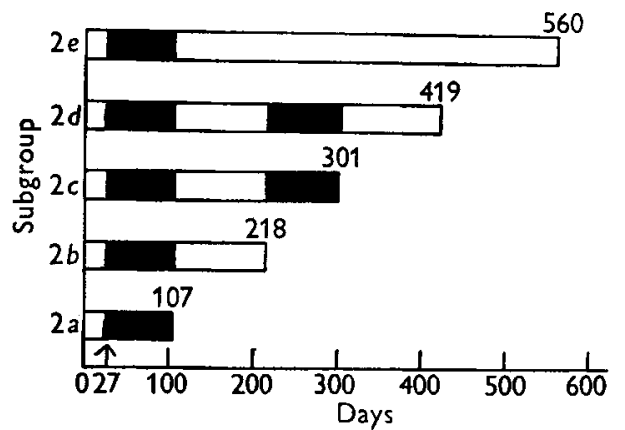

Fig. 2. Dietary periods in Exp. 2.

Black areas correspond to periods when diet contained ${ }^{45} \mathrm{Ca}$. Figures indicate ages of rats in days at end of experiment.

rotating steel plate of a lens-grinding machine, but it was not always possible to obtain in this way sections in exactly the same plane. However, a sufficient number of specimens was available for differences in results due to slightly different section planes to be recognized as such.

The sections were kept reasonably free from contamination with grinding powder by frequent washing during grinding, in which very little abrasive and plenty of water was used.

In this way specimens were obtained consisting of approximately half of the original bone, including epiphyses, in complete sagittal section. Autoradiographs were prepared by placing the polished sections in direct contact with X-ray film for a suitable period, usually a few days to a week. A second microscope slide was placed over the film covering the section, and the assembly was held together with rubber

* In further work by the same autoradiographic technique now in progress, Marco Resin $26 c$ is being used for embedding the bones, for which purpose it has advantages over paraffin wax. 
bands, giving sufficient rigidity during exposure and a sufficiently good contact without pressure or chemical effects on the film, as films exposed in this way to nonradioactive bone sections were entirely unaffected.

Several types of X-ray film were tried, Ilford 'Industrial C' being found suitable for general use. Ilford 'Dental' film, which has a somewhat finer grain but is correspondingly slower than 'Industrial C', was also satisfactory and more suitable for microscopic examination. Standard X-ray film-processing technique, as recommended by the makers was followed at the end of the exposures, development being carried out in developer I.D. $19 b$ for $4 \mathrm{~min}$ at $18^{\circ}$, fixing in acid solution for $15 \mathrm{~min}$ and washing in running water for about $\mathrm{I} h$. To prevent subsequent damage, each film was mounted between thin microscope slides bound with lantern-slide tape.

The autoradiographs were examined with a projection microscope with magnifications up to 30 , and dimensional measurements were made on them by means of micrometer screws provided for moving the plate holder of the instrument. Similar measurements were made on the actual bone sections by viewing them in the microscope by reflexion, and correlations between sections and their autoradiographs were thus obtained.

Estimations of the specific activity in localized regions of the bone sections were made from measurements of the optical densities of the corresponding regions in the autoradiographs. These were made with a microphotometer with which it was possible to scan the film along a given line and plot the density as a function of distance. The scans were made in most instances transversely across the diaphyseal regions at right angles to the axis of the bone. The specific activity values derived from such measurements were proportional to the number of ${ }^{45} \mathrm{Ca}$ atoms per unit area in a thin layer of fixed thickness at the surface of the bone section. The film was calibrated by making exposures for various times to a standard radioactive source, and the density as measured on the microphotometer was found to be a linear function of the exposure.

Comparisons between autoradiographs from different groups of rats were conveniently made by superposing the films, a procedure that provided a convincing means of demonstrating certain aspects of bone growth.

\section{RESULTS}

Remarkably good reproducibility in the appearance of autoradiographs was obtained within each of the subgroups of both Exps. I and 2 and of others that we have carried out over the past 2 or 3 years; the examples shown in the plates are given as typical of the observed patterns.

\section{Experiment I}

The autoradiographs obtained showed the development of the femur and humerus from the age of 30 days through the period of rapid growth. Representative enlarged prints from the original films are shown in $\mathrm{Pl}$. I and representative low-power photomicrographs of the diaphyseal regions in Pl. 2.

Anterior wall of femur. Early growth of the anterior wall of the femoral diaphysis occurred by both periosteal and endosteal apposition of new radioactive bone on to 
the existing non-radioactive 30-day-old cortex. The periosteal deposit predominated at the proximal end, tapering off towards the central region of the shaft, whereas the endosteal deposit was located mainly at the distal metaphysis, but extended also into the diaphysis. Throughout the period of the experiment the periosteal layer of radioactive bone increased steadily in thickness and advanced towards the distal metaphysis, meeting the endosteal deposit at the age of about 60 days. At the same time the endosteal layer extended proximally into the diaphysis until the whole of the non-radioactive cortex was covered; thereafter, further endosteal activity was restricted to the distal metaphyseal region.

Posterior wall of femur. The presence of the 30 -day-old cortex lining the marrow cavity was detected only in the earliest stages. Growth in thickness took place entirely by periosteal apposition of new bone, endosteal apposition being restricted to the metaphysis from the beginning. Resorption of bone along the endosteal surface of the diaphysis proceeded steadily until nearly all the non-radioactive bone had been removed, and in the older subgroups the posterior wall was composed entirely of new radioactive bone, apart from a small intrusion representing the curved metaphyseal cortex of the 30 -day-old femur.

Information of a more quantitative nature about diaphyseal growth was derived from dimensional measurements on the autoradiographs and on the corresponding bone sections made with the projection microscope, and also from plots of the variation in optical density in the films made with the microphotometer. In both, the measurements were made along a line perpendicular to the bone axis passing across the diaphysis in the region occupied by the layer of the 30-day-old 'non-radioactive' bone. Dimensional measurements were made with the object of proving that the thickness of this layer remained constant throughout the experiment and that the adjacent radioactive layers were, therefore, truly appositional rather than due to exchange of the radioactive blood $\mathrm{Ca}$ with the $\mathrm{Ca}$ already incorporated in the $3^{0}$-dayold bone. The results are shown in Fig. 3; measurements of the total thickness of the cortex forming the anterior wall of the diaphysis made on the bone sections agreed well with the corresponding measurements taken from the autoradiographs, and the measured thickness of the 30-day-old layer within the cortex, as determined from the autoradiographs, did not vary significantly among the age groups of the experiment. The constant value obtained agreed well with the result given for the total thickness of the cortex by extrapolating the experimental total-thickness curve to 30 days. Similar results from Exp. 2 are also included in Fig. 3.

Microphotometric measurements were made with the object of comparing the specific activities of bone material forming the 30-day-old layer in the anterior wall of the femur with that in newly formed regions, such as the posterior periosteal deposit and new longitudinal growth at the distal end of the diaphysis. Fig. 4 shows plots obtained for subgroups $\mathrm{I} a$ and $\mathrm{I} g$ (ages of rats 47 and $\mathrm{r} 29$ days, respectively) arranged along the horizontal axis so that the minimums corresponding to the 30-dayold bone in the anterior wall coincided and were, therefore, in the correct relative positions to show how transverse growth occurred.

The finite density recorded at the minimum in the anterior wall showed that the 


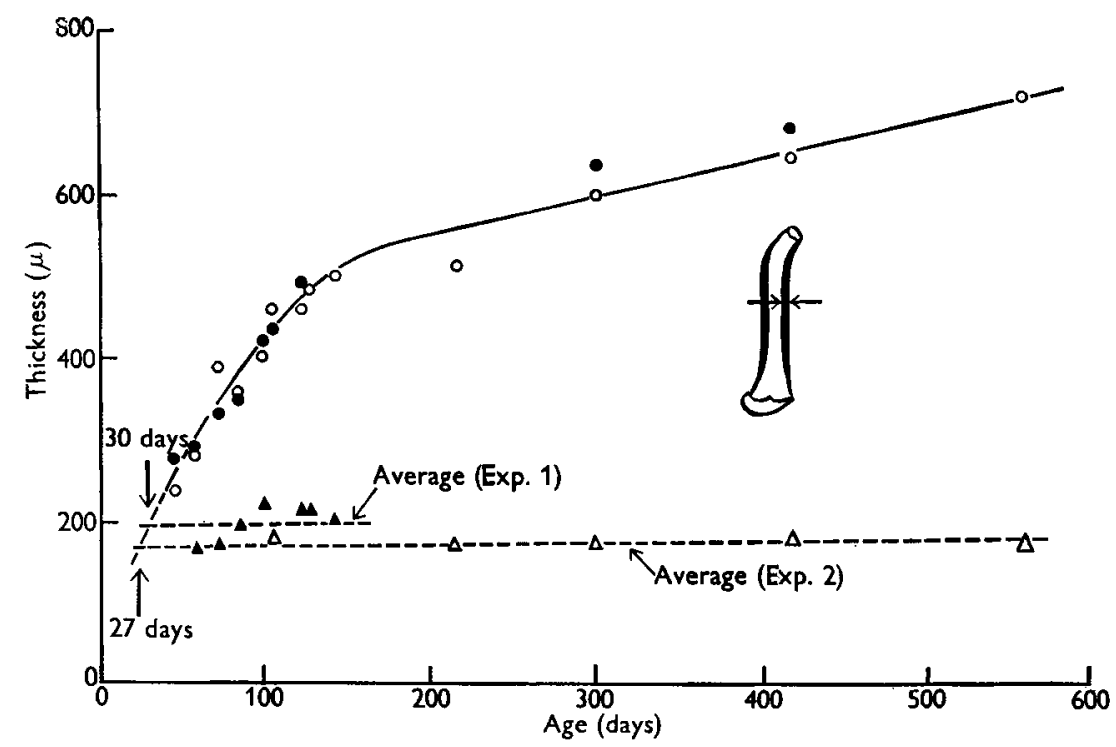

Fig. 3. Thickness $(t)$ of the anterior diaphyseal cortex of the femur, and of the 'non-radioactive' layer within the cortex. $O$, total thickness measured from bone sections; 0 , total thickness measured from autoradiographs; $\Delta$, thickness of 30 -day-old 'non-radioactive' layer measured from autoradiographs of Exp. I; $\triangle$, thickness of 30-day-old 'non-radioactive' layer measured from autoradiographs of Exp. 2.

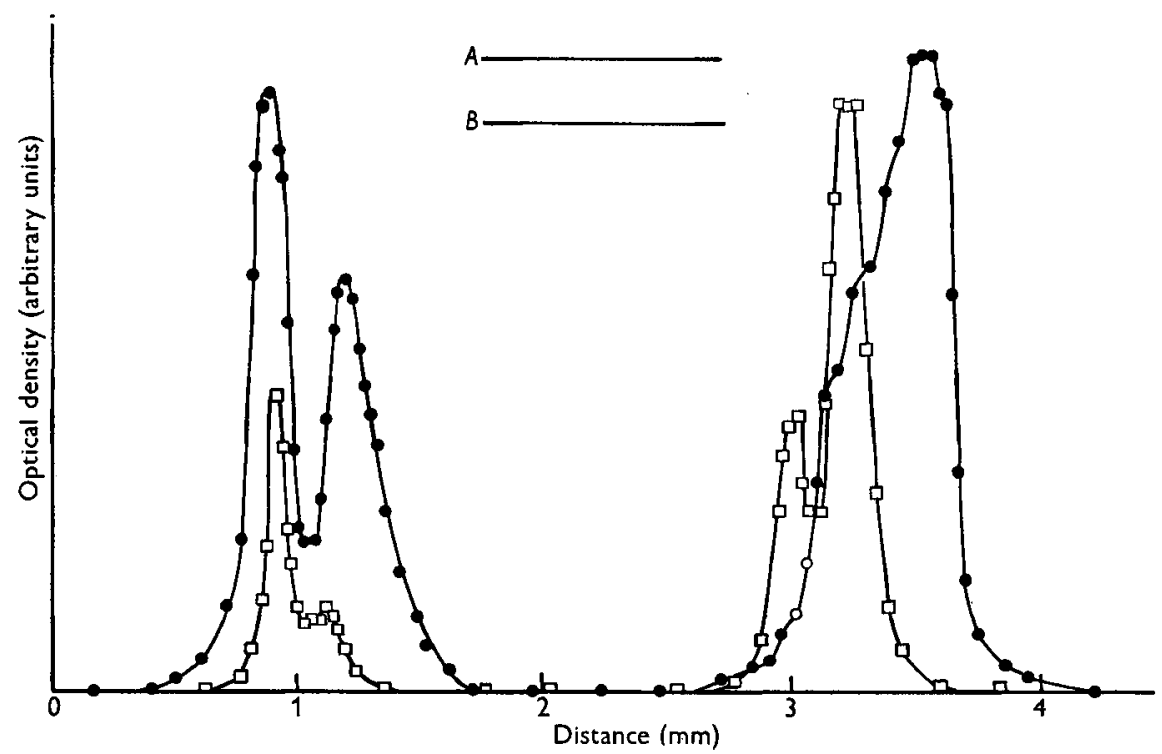

Fig. 4. Exp. I. Transverse variation of optical density across the femoral diaphysis in the region containing the 30-day-old 'non-radioactive' bone. 9 , subgroup Ig; $\square$, subgroup I $a$. The horizontal lines $A$ and $B$ indicate the densities in the regions corresponding to newly formed radioactive bone at the distal end of the shaft in the respective bones. The density is proportional to the specific activity of the bone in the surface of the section. 
bone material in the 30-day-old layer was not completely non-radioactive; this was most probably due to exchange of $\mathrm{Ca}$ ions throughout the bone material (see p. 245). The specific activity of this layer relative to that of bone material formed during the period of radioactive diet was calculated, and the results are presented in Table $\mathbf{I}$. In many instances, these measurements were made on both femora from all four animals in a given subgroup, and the consistency of the results was such that random errors were probably not greater than $10 \%$. It was, of course, unnecessary to take the radioactive decay of ${ }^{45} \mathrm{Ca}$ into account in the calculations, since only comparisons from one region to another in individual films were involved. In subgroup $\mathrm{r} a$ the initial deposits of radioactive bone at the endosteal and periosteal surfaces of the anterior wall only just extended to the line along which the microphotometer scan was made and had a lower specific activity than the maximum attained by newly formed bone. In the posterior wall, the specific activity did attain this maximum at

Table I. Exp. x. Comparison of specific activities in the 30-day-old 'non-radioactive' region, and in the newly formed radioactive region of the long bones

(The specific activities are given in arbitrary units, and each represents the mean result for at least three animals in the corresponding subgroup)

$\begin{array}{clcccc}\text { Subgroup } & \text { Bone } & \begin{array}{c}\text { Age of } \\ \text { animal } \\ \text { (days) }\end{array} & \begin{array}{c}\text { Specific activity } \\ \text { in 'non-radio- } \\ \text { active' region }\end{array} \text { in newly formed } \\ \text { radioactive region } & \begin{array}{c}\text { Ratio of } \\ \text { specific } \\ \text { activities }\end{array} \\ \text { Ia } & \text { Femur } & 47 & 0.13 & 0.83 & 0.16 \\ \text { Ib } & \text { Femur } & 60 & 0.11 & 0.77 & 0.14 \\ \text { Ic } & \text { Femur } & 74 & 0.22 & 1.10 & 0.15 \\ \text { Id } & \text { Femur } & 87 & 0.15 & 0.84 & 0.18 \\ \text { I } e & \text { Femur } & 101 & 0.16 & 0.80 & 0.20 \\ \text { If } & \text { Femur } & 124 & 0.20 & 0.85 & 0.25 \\ \text { Ig } & \text { Femur } & 129 & 0.21 & 0.89 & 0.23 \\ \text { Ig } & \text { Humerus } & 129 & 0.31 & 1 \cdot 30 & 0.24\end{array}$

the periosteal surface, but in general the specific activity decreased irregularly towards the endosteal surface. Fig. 4 shows a subsidiary maximum at this endosteal surface; it corresponded to a small spicule of bone projecting into the marrow cavity.

Comparison of the plots for the two subgroups showed the extent of metabolic activity in the posterior wall of the femur. By the age of 129 days, a large fraction of the young bone at the position to which the plots refer had been replaced by the processes of endosteal resorption and periosteal apposition.

Humerus. The humeral autoradiographs showed a simpler growth process, involving little resorption of the 3 o-day-old diaphysis. Growth took place by the apposition of new radioactive bone at certain parts of both endosteal and periosteal surfaces of the cortex, with the result that the form of the $3^{0}$-day-old bone, as indicated by the 'non-radioactive' layers, was retained within the diaphysis in all subgroups of the experiment. Microphotometer measurements gave similar specific-activity ratios to those obtained from the femora, as indicated in Table I. 
Experiment 2

In the second series of autoradiographs the investigation was extended to the growth and metabolism of bone in adult rats. The first subgroup, $2 a$, was killed at the age of 107 days, the animals having received radioactive $\mathrm{Ca}$ from the $27^{\text {th }}$ day.

Autoradiographs of femora and humeri (PI. 3) showed characteristics similar to those previously described for Exp. I; the 27-day-old bone was clearly distinguished within the diaphyseal cortex. No significant differences in the growth pattern assignable to the effects of the high- and low-Ca diets were detected at this stage of the experiment; the bones shown in $\mathrm{Pl} .3$ are from animals receiving the low-Ca diet throughout.

Animals in the second subgroup, $2 b$, received the non-radioactive diet from the age of 107 days for a further period of about 3 months and were killed at the age of 218 days. Longitudinal growth at the distal metaphysis of the femur and at the proximal metaphysis of the humerus was shown by the addition of non-radioactive bone ( $\mathrm{Pl} .3$ ). The epiphyses retained a considerable amount of the radioactive $\mathrm{Ca}$ that had been incorporated during the first period of the experiment and were sharply differentiated from the metaphyses at the epiphyseal cartilage. The 27 -day-old bone material was still retained within the diaphyses and was, in fact, found in all the subgroups.

The complete growth mechanism was shown very clearly in the autoradiographs from subgroup $2 c(\mathrm{Pl} .3)$, in which a further period of radioactive diet gave rise to new deposits of radioactive bone material unambiguously identified by virtue of a higher specific activity of the dietary $\mathrm{Ca}$ (cf. p. 237).

In the femoral diaphysis, the new bone was located at the periosteal surface, extending from the proximal end, where it covered also the articular surface of the epiphysis, towards the distal metaphysis, with gradual reduction in thickness. This layer was separated from the 107-day-old radioactive bone by a similar non-radioactive layer, which clearly corresponded to periosteal apposition during the period from 107 to 218 days. In the distal metaphysis, the new radioactive deposit was located at the endosteal surface, and endochondral activity was indicated by the entry of radioactive $\mathrm{Ca}$ into the epiphyseal plate and the spongiosa.

Similar phenomena were observed in the humeral autoradiographs from this subgroup; periosteal deposits covered certain regions of the diaphysis, and endosteal bone formation occurred in the proximal metaphysis.

During the next period of the experiment, from 301 to 4 I9 days (subgroup $2 d$ ), a further slight increase in length took place in both femur and humerus. The autoradiographs showed changes due to this growth in the sub-epiphyseal region of the metaphyses ( $\mathrm{Pl}$. 3); further periosteal apposition would not be detectable, since the bone formed would be non-radioactive, but the fact that the periosteal layers of radioactive bone formed during the previous period still remained after the subsequent 3 months on non-radioactive diet showed that these did in fact represent the deposition of compact bone rather than an exchange of $\mathrm{Ca}$ in the surface layers or in the periosteum.

Animals in the final subgroup, $2 e$, which had received radioactive $\mathrm{Ca}$ up to the ro7th day and the non-radioactive diet for a further period of about 18 months, had 
a distribution of the 107-day-old radioactive bone material similar to that observed in subgroup $2 b$, the only obvious distinction between the two subgroups being the greater amount of non-radioactive growth at the distal end of the diaphysis in the older bone. Comparison of optical densities in representative autoradiographs from subgroups $2 a, 2 b$ and $2 e$, which had all been given the same exposure when prepared together at the end of the experiment, showed no significant differences in the specific activities of the 107-day-old bone material. The measurements are shown in Table 2, together with those corresponding to the 27-day-old non-radioactive layer. The ratio of the specific activities of the bone material in these regions is also listed; the results are similar to the corresponding values obtained in Exp. I (cf. Table I). Visual examination showed that the epiphyses retained a considerable proportion of the radioactive $\mathrm{Ca}$ that had been incorporated at the age of 107 days, a result indicating that exchange of $\mathrm{Ca}$ in the epiphyseal bone was less extensive in these adult rats than in the young rats of Exp. I.

Table 2. Exp. 2. Comparison of specific activities in the 30-day-old 'non-radioactive' region and in the 107-day-old radioactive region of the long bones

('The specific activities are given in the same arbitrary units as in Table $I$, and each represents the mean result for at least two animals in the corresponding subgroup.)

$\begin{array}{clcccc}\text { Subgroup } & \text { Bone } & \begin{array}{c}\text { Age of } \\ \text { animal } \\ \text { (days) }\end{array} & \begin{array}{c}\text { Specific activity } \\ \text { in'non-radio- } \\ \text { active' region }\end{array} & \begin{array}{c}\text { Specific activity } \\ \text { in ro7-day-old } \\ \text { radioactive region }\end{array} & \begin{array}{c}\text { Ratio of } \\ \text { specific } \\ \text { activities }\end{array} \\ 2 a & \text { Femur } & 107 & 0.24 & 0.88 & 0.27 \\ 2 b & \text { Femur } & 218 & 0.25 & 0.94 & 0.27 \\ 2 e & \text { Femur } & 560 & 0.22 & 0.88 & 0.25 \\ 2 e & \text { Humerus } & 560 & 0.22 & 0.88 & 0.25\end{array}$

Regions of bone formed in longitudinal growth during a non-radioactive dietary period subsequent to a radioactive period gave rise to detectable densities in the autoradiographs, owing, no doubt, to the fact that for some time after a change from a radioactive to a non-radioactive diet the blood $\mathrm{Ca}$ was in part derived from the resorption of radioactive bone. This effect was not sufficiently marked to obscure the sharp boundaries that separated regions of radioactive and non-radioactive bone, and the relationship of these boundaries to the form of the bone cortex at the time corresponding to the dietary changes was clearly shown by superposing autoradiographs from appropriate subgroups. This could be done accurately by using the labelled and unlabelled layers within the diaphyses as guides to alignment. Pl. 3 shows the superposition of femoral and humeral autoradiographs from subgroups $2 a$ and $2 c$. In all instances the boundaries mentioned above resulted from the simple addition of new bone to existing cortical surfaces.

\section{Effect of the high- and low-calcium diets}

The results so far described refer to general growth characteristics observed in all animals, whether receiving the high- or the low-Ca diet. However, when femoral autoradiographs were superposed, as described in the previous section, close correspondence between subgroups was obtained only when the two bones compared 
had been produced on the same diet. Animals that had received the high-Ca diet, particularly those in the younger subgroups, tended to have longer femora. This was paralleled by a similar tendency towards better growth among these animals. It is of interest that previous experiments (Henry \& Kon, 1953) showed animals given the high-Ca diet to have heavier bones than litter-mates given the low-Ca diet.

On examining the autoradiographs for small differences in the growth patterns that might correspond to the effects of the two levels of $\mathrm{Ca}$ intake, significant features were found, particularly in the femora from subgroup $2 c$. The endosteal growth of radioactive bone during the age period from 218 to 302 days, though confined mostly to the curved metaphyseal regions, extended along the endosteal surface of the anterior wall into the cylindrical diaphysis, and this extension was more marked in the animals that had received the low-Ca diet. Pl. 4 shows two pairs of femoral autoradiographs, each containing a representative picture from the high- and the low-Ca diet groups for nearly identical section planes; these illustrate the differences described above, and the superposed print in Pl. 4, (3) shows the disparity in the lengths of the bones.

A similar pair of autoradiographs from subgroup $2 d(\mathrm{Pl} .4,(4)$ and (5)) also showed a difference in length, but the difference in the endosteal deposits of radioactive bone just described for subgroup $2 c$ did not persist through the succeeding period of non-radioactive diet.

Examination of humeral autoradiographs for similar effects of different dietary $\mathrm{Ca}$ levels showed no detectable differences attributable to this cause.

\section{DISCUSSION}

The results of the study can be conveniently discussed in terms of two main aspects, that of exchange of calcium in living bone material, independently of growth, and that of the true growth process.

\section{Exchange of calcium in living bone}

The figures in Tables $\mathrm{x}$ and 2 give a definite indication that interstitial exchange of $\mathrm{Ca}$ occurs in the compact bone of the living rat. Such a process most suitably accounts for the observed specific activity in the bone material formed up to the age of about 30 days, during which time the animals had received no radioactive $\mathrm{Ca}$. The regions of the diaphysis containing this bone material are well suited as a subject for the discussion of the exchange process. In both femur and humerus there exist such regions, where no complications arise due to resorption of bone. Further, it has been reported previously (Leblond et al. 1950 ) that exchange occurs more extensively in young bone.

The figures in Table $\mathrm{I}$ indicate that during the 2 weeks after the 3 oth day in Exp. I $14 \%$ of the bone $\mathrm{Ca}$ was renewed from that entering the circulation and that this fraction rose during the subsequent few weeks, soon reaching a maximum value of about $24 \%$ (cf. Table I, I20-day-old rats). Approximately the same fractional exchange of $\mathrm{Ca}$ took place in Exp. 2, as indicated in Table 2; for subgroups $2 b$ and $2 e$, the skeleton was in an environment of non-radioactive body fluid for long periods after the initial radioactive treatment up to the ro7th day. The constancy of the ratios 
in the last column of the table thus indicates that exchange was approximately uniform throughout the entire compact bone. The figures for the specific activity of the 107day-old radioactive region in subgroups $2 a, 2 b$ and $2 e$ suggest that exchange was in any event negligible in bones older than 107 days, but it must be emphasized that many factors influence the measured absolute values of optical densities, and the detection of small differences in density between similar regions in different films is less certain than the measurement of relative densities from point to point in an individual film. However, it is certain from the results that exchange of $\mathrm{Ca}$ in adult bones is considerably less pronounced than in young bones.

It seems worth pointing out that visual examination alone is not a very sensitive test for low optical densities, particularly when the regions examined are bounded by others of high density. For example, it was not possible to distinguish with the eye between the densities of the regions of film corresponding to the 3 -day-old bone material and the background of unexposed film.

The problem of the renewal of bone salts by exchange has been studied by many workers using ${ }^{32} \mathrm{P}$ and ${ }^{45} \mathrm{Ca}$, in most instances by the technique of dividing the bones into representative portions and determining the specific activities of the $\mathrm{Ca}$ or $\mathrm{P}$ content of each. This has usually been done at short intervals after the administration of a single dose of the tracer by injection or by stomach tube. The eventual distribution of labelled bone is then complicated by the rapid variation with time of the specific activity of the blood after administration and also by the fact that any measured specific activity is an average value for a given portion of bone in which the labelled salts may be highly localized.

Experiments of this kind were carried out with ${ }^{32} \mathrm{P}$ by Manly \& Bale (1939), Manly, Hodge \& Manly (1940) and Neuman \& Riley (1947). Falkenheim, Neuman \& Hodge (1947) examined exchange in powdered bone suspended in solutions containing ${ }^{32} \mathrm{P}$. The general conclusion was that in the presence of radioactive solution or body fluid bone material became labelled by exchange, and the mechanism of the process was described by Neuman \& Riley (1947) in terms of a rapid initial ionic exchange at the surface of micro-crystals of bone salt, limited by the very slow diffusion of ions through the volume of the crystals.

More recently similar measurements have been carried out with ${ }^{45} \mathrm{Ca}$ by Armstrong \& Barnum (1948), by Harrison \& Harrison (1950) and, in vitro, by Falkenheim, Underwood \& Hodge (195 I). Armstrong \& Barnum (1948) used only one adult rat and, because of the low specific activity then available, administered a very large dose of labelled $\mathrm{Ca}\left(122 \cdot 3 \mathrm{mg}\right.$ ) simultaneously with a dose of ${ }^{32} \mathrm{P}$. Exchange of both elements in the calcified tissues to approximately the same extent was observed at the end of a 5-day period. Harrison \& Harrison (1950) studied the uptake of radio-Ca by the skeleton under more favourable conditions and concluded that the amount of the administered dose of labelled $\mathrm{Ca}$ subsequently recovered from the calcified tissues was far too great to be accounted for by growth alone and must have been incorporated mainly by exchange. They estimated that $50 \%$ of the skeletal Ca in 6-8-week-old rats was renewed by exchange in $45 \mathrm{~h}$ and concluded from this that exchange was too pronounced to permit the use of the tracer method for studying bone growth. 
A similar conclusion had been reached by Neuman \& Riley (I947) from their work with ${ }^{32} \mathrm{P}$.

The in vitro experiments of Falkenheim et al. (195I) were similar to those done previously with ${ }^{32} \mathrm{P}$ and again demonstrated the possibility of exchange between bone $\mathrm{Ca}$ and $\mathrm{Ca}$ in a surrounding solution. The authors estimated that about $20 \%$ of the $\mathrm{Ca}$ and $\mathrm{P}$ atoms in bone were involved in a fairly rapid exchange, after which the process continued at a much reduced rate, and pointed out that this figure agrees well with the fraction of atoms that would be expected to occupy surface sites in the microcrystals of bone salt.

The results of the present study, therefore, agree fairly well with those of the in vitro experiments, but not with those of Harrison \& Harrison (1950), who consider that a much greater exchange occurs. It is probable that the in vitro method is more quantitative than the other experiments cited above, but it suffers from the disadvantage of involving non-physiological conditions. Localized comparative measurements of specific activities from autoradiographs by photometric methods avoid the disadvantages, mentioned above, that attach to the determination of average specific activities of the $\mathrm{Ca}$ or $\mathrm{P}$ contents of relatively large portions of bone. To be completely satisfactory, however, the photometric technique demands careful control of experimental conditions. It should be pointed out that all likely sources of systematic error in our method of measurement would give for the fractional exchange of $\mathrm{Ca}$ in cortical bone results too high rather than too low.

\section{Growth mechanism of the femur}

In general, the results on bone growth confirm well-established views, and agree with those of Payton (1932), who used madder, and of Leblond et al. (1950), who used ${ }^{32} \mathrm{P}$.

The ${ }^{45} \mathrm{Ca}$ autoradiographs obtained in the present work show in a particularly striking manner that growth of the long bones is achieved by a unified mechanism embracing both transverse and longitudinal growth, together with remodelling where this is necessary. Analysis of the autoradiographic patterns shows that at all stages of development the necessity for remodelling largely determines the mode of growth.

Fig. 5 shows a diagrammatic reconstruction of the femoral growth mechanism, embodying results from both Exps. I and 2. Three stages of development, corresponding roughly to the ages of 30 , 100 and 200 days, are shown. Widening of the marrow cavity and increase of cortical thickness occur rapidly during early stages of growth, the former by resorption of bone at the adjacent surface of the diaphysis and the latter principally by periosteal apposition of new bone material. It is significant that endosteal resorption is maximal in the posterior wall of the femur, where, particularly in the young rat, the cortex has a pronounced curvature in the axial plane, and is zero in the anterior wall, where curvature is very slight. Growth in diameter thus occurs in such a way as to eliminate by resorption only those parts of the existing diaphysis that cannot, on account of curvature, be incorporated into the mature structure. Fig. 5 shows how the posterior wall is extensively remodelled during early growth, while the anterior wall grows entirely by accretion at both 
endosteal and periosteal surfaces. These surface layers are deposited in such a way as to modify slightly the inclination of the anterior wall to the axis of the bone, thus bringing the two opposite walls, as seen in sagittal section, into closer parallelism and forming the characteristic cylindrical shape of the diaphysis. This change in direction is evidenced by the fact that the $27-30$-day-old layer in the anterior wall always lies diagonally across the cortex.

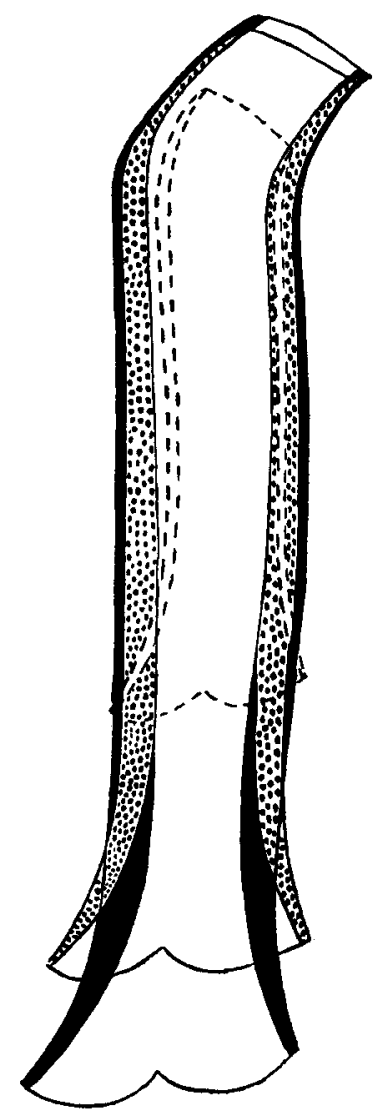

Femur

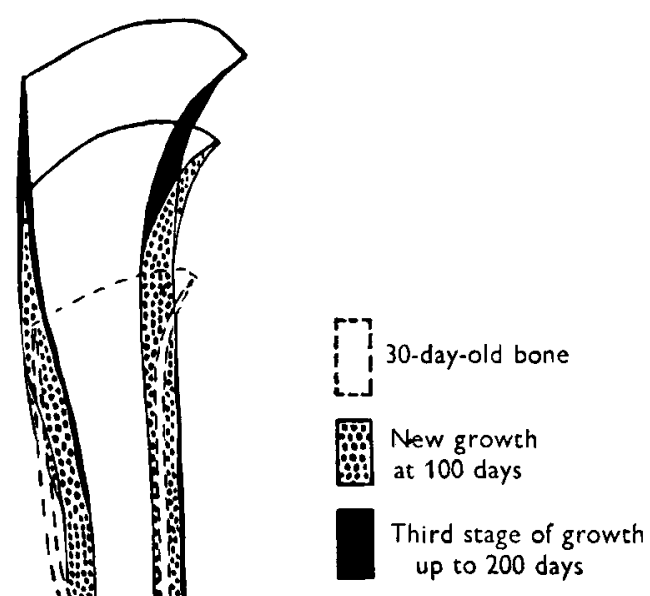

Humerus

Fig. 5. Diagrammatic representation (not to scale) of three stages in the growth of the femur and humerus in the rat.

In subsequent growth, endosteal apposition becomes localized mainly in the distal metaphysis, though there remains a tendency for this deposit to extend along the anterior wall into the cylindrical diaphysis. 'Together with periosteal resorption, this has the effect of remodelling the distal end of the anterior wall, producing an inward curvature that tends to bring the cortex over towards the posterior wall. In this way the amount of remodelling needed in the more sharply curved posterior wall of the metaphysis is reduced, and the whole remodelling process is distributed more uniformly around the metaphysis instead of being concentrated where the curvature is greatest. 


\section{Effect on femoral growth of the different calcium levels of the diet}

It is suggested that the phenomena observed in the autoradiographs of the femora from subgroup $2 c$ and illustrated in Pl. 4 can be interpreted in terms of a mechanism for adjusting the diaphyseal diameter to suit the rate of intake of $\mathrm{Ca}$ by the animal. Up to the age of 30 days, all animals had access to the adequate supply of $\mathrm{Ca}$ in the stock-colony diet, and their rapid growth was not limited by the supply of Ca. From the beginning of the experimental period, at the 3 oth day, bone growth was governed by the need for remodelling the curvature of the young diaphysis, and this process defined the minimum diameter of the proximal section of the adult diaphysis. Animals receiving the low-Ca diet from the 3 oth day would be expected to grow at a reduced rate compared with the high-Ca animals if the $\mathrm{Ca}$ supply were insufficient to effect the diaphyseal remodelling and produce longitudinal growth simultaneously at a normal rate. We may say that the diaphyseal diameter imposed by the curvature of the young bone is 'appropriate' to a Ca intake at least equal to that derived from the stock diet. The diameter can be modified only when sufficient longitudinal growth has occurred at the distal end to allow a gradual change to occur, and it is suggested that this does, in fact, occur by endosteal deposition in the anterior wall, with compensating periosteal resorption. The process is simply an extension of the normal growth mechanism, but a given cortical thickness is retained with an overall saving in bone material by a reduction in diameter to a value that may be called 'appropriate' to the lower $\mathrm{Ca}$ intake afforded by the low-Ca diet. The part of the shaft affected in this process is that formed during early adult life when longitudinal growth is still appreciable.

It is possible, though this has not been proved in the present study, that at a still later stage, when the periosteal surface of this region of the diaphysis has become a site of apposition rather than resorption, and when longitudinal growth has virtually ceased, further modification by periosteal apposition and endosteal resorption may restore the narrowed region to a more normal size and shape. This may explain the finding in the femoral autoradiographs from subgroups $2 d$ (Pl. 4, (6) and (7)) that the diaphyseal extension of the endosteal radioactive deposit in the anterior wall was similar in both the high-Ca and low-Ca groups. The scheme is certainly consistent with the observed variation with age in the weights of rats and of bones (Henry \& Kon, 1953).

\section{Growth mechanism of the humerus}

The total growth mechanism observed in the humerus is somewhat different from that found for the femur on account of the difference in shape of the two bones. The humeral diaphysis has a less defined cylindrical region, the diameter as seen in sagittal section increasing steadily from the distal extremity towards the proximal metaphysis, the posterior wall of which has a very pronounced curvature, whereas the anterior wall is straight in this region. The diaphysis itself has greater curvatures in the anterior wall, which projects outwards towards the proximal end to form the deltoid tuberosity. Details of the observed growth mechanism are shown in the diagrammatic representa- 
tion in Fig. 5; the sites of apposition are so disposed as to remodel the curvatures of the cortex during growth.

An adjustment of diameter to suit particular dietary circumstances, as suggested in discussing the growth of the femur, could proceed gradually in the humerus throughout the growth period, because of the different mode of growth. It is likely that this accounts for the fact that no effects attributable to the different dietary Ca levels were observed on the growth of the humerus.

\section{SUMMARY}

I. The radioactive isotope ${ }^{45} \mathrm{Ca}$ has been used as a tracer to study bone growth and calcium metabolism in young and adult rats. A simple autoradiographic technique, for which this isotope is particularly suited, has been applied to study the localization of bone salts incorporated in the long bones during specific periods.

2. By means of micro-photometric measurements, the optical densities in various regions of the autoradiographs have been compared and quantitative results for the exchange of bone $\mathrm{Ca}$ have been obtained. This method was used in preference to that involving measurements of the specific activity of $\mathrm{Ca}$ extracted from macroscopic portions of the bone, because with it a clear distinction could be made between true exchange and true growth. The results agreed with those of previously reported in vitro experiments with powdered bone suspended in solutions containing ${ }^{32} \mathrm{P}$, rather than with those obtained in animal experiments involving use of the macroscopic specific-activity method.

3. In the age period from 4 to 6 weeks approximately $14 \%$ of the 4 -week-old diaphyseal bone $\mathrm{Ca}$ in the femur and the humerus was renewed by exchange, and this figure increased to a maximum of about $24 \%$ by the 16 th week.

4. Exchange of $\mathrm{Ca}$ was considerably less extensive in the bones of adult rats.

5. The mechanism of growth in the femur and humerus is discussed in detail. Sites of apposition and resorption are so disposed as to produce a unified process of growth and remodelling and are closely related to the curvatures of the bone cortex. General agreement was found with the results of previous work in which madder had been used.

6. Some evidence was found of a modification in the normal growth mechanism of the femur when the $\mathrm{Ca}$ intake was changed from adequate to slightly suboptimal. It is suggested that this modification was such that less bone material was needed to produce a given cortical thickness.

7. A similar effect was not observed in the humerus, probably owing to a difference in the mode of growth.

The authors wish to acknowledge the valuable assistance given by Miss M. V. Chapman in the care and feeding of the experimental animals and by Miss A. C. Phillips and by Mrs E. M. Wiltshire in preparing bone sections and autoradiographs. 


\section{REFERENCES}

Armstrong, W. D. \& Barnum, C. P. (1948). F. biol. Chem. 172, 199.

Bourne, G. H. (1952). Biol. Rev. 27, 108.

Brash, J. C. (I934a). Edinb. med. F. 4I, 305.

Brash, J. C. (1934b). Edinb. med. F. 41, 363.

Falkenheim, M., Neuman, W. F. \& Hodge, H. C. (1947). F. biol. Chem. r69, 7 3.

Falkenheim, M., Underwood, E. E. \& Hodge, H. C. (1951). F. biol. Chem. 188, 805.

Folley, S. J., Ikin, E. W., Kon, S. K. \& Watson, H. M. S. (1938). Biochem. F. 32, r988.

Harrison, H. E. \& Harrison, H. C. (1950). F. biol. Chem. 185, 857.

Henry, K. M. \& Kon, S. K. (1947). Biochem. F. 4r, r69.

Henry, K. M. \& Kon, S. K. (1952). F. Dairy Res. 19, 216.

Henry, K. M. \& Kon, S. K. (1953). Brit. F. Nutr. 7, 147.

Hunter, J. (I837). Works, Palmer's edition. London: Longman, Ress, Orme, Brown, Green and Longman.

Leblond, C. P., Wilkinson, G. W., Bélanger, L. F. \& Robichon, J. (r950). Amer. Э. Anat. 86, 289.

Manly, M. L. \& Bale, W. F. (1939). F. biol. Chem. 129, 125.

Manly, R. S., Hodge, H. C. \& Manly, M. L. (1940). F. biol. Chem. 134, 293.

Neuman, W. F. \& Riley, R. F. (1947). F. biol. Chem. 168, 545.

Payton, C. G. (1932). F. Anat., Lond., 66, 414.

\section{EXPLANATION OF PLATES}

\section{Plate I}

Exp. I. Autoradiographs of femora and humeri representing subgroups $\mathrm{I} a, \mathrm{I} b, \mathrm{I} c, \mathrm{I} e, \mathrm{I} f$ and $\mathrm{I} h$.

Femora. In the 47-day-old femur the non-radioactive (black) bone material formed up to the age of 30 days can be seen in both anterior and posterior walls of the proximal half of the cortex. In subsequent subgroups the anterior wall has received endosteal and periosteal additions of new radioactive material, the periosteal apposition predominating in the older animals. The posterior wall has received only periosteal apposition throughout the experimental period, and the amount of 30-day-old bone material has been reduced by endosteal resorption.

Humeri. A considerable amount of the 30-day-old cortex has been retained throughout the experimental period, new radioactive bone having been added to it at certain periosteal and endosteal sites.

A less intense autoradiographic reaction at the growing ends of the bones in subgroup $1 h$ is due to the use, in the final stages of the experiment, of a fresh batch of diet having slightly lower specific radioactivity.

\section{Plate 2}

Exp. I. Low-power photomicrographs of femoral autoradiographs, showing in further detail the sites of the 30-day-old non-radioactive (white) bone, and the subsequently added radioactive bone.

\section{Plate 3}

Exp. 2. Autoradiographs of femora and humeri representing subgroups $2 a, 2 b, 2 c, 2 d$ and $2 e$. Longitudinal growth has occurred at the distal end of the femoral diaphysis and at the proximal end of the humeral diaphysis.

The autoradiographs representing subgroup $2 c$ show how apposition of new bone at the periosteal and endosteal surfaces of the cortex conforms to a unified growth mechanism providing for the necessary remodelling of the diaphysis. In subgroup $2 d$ slight changes are visible only in the metaphyseal regions; non-radioactive $\mathrm{Ca}$ has replaced the radioactive mineral initially present in the epiphyseal plates and in the adjacent region of the metaphyses. The humeral autoradiograph in this subgroup shows midway along the posterior diaphyseal wall an effect due to migration of the nutrient foramen. Radioactive $\mathrm{Ca}$ deposited during the age period 2 I8-30 I days is seen lining the lower edge of the foramen; this, together with resorption at the upper edge, results in a movement of the canal towards the proximal end of the shaft.

The autoradiographs from subgroup $2 e$ demonstrate the stability with which bone retains $\mathrm{Ca}$ in regions not undergoing resorption. At the age of 560 days the femur and humerus have retained the $3^{\circ}$-day-old bone, and the subsequent radioactive diaphyseal growth, in substantially unaltered form (cf. subgroups $2 a$ and $2 b$ ). 
Apart from longitudinal growth, the only significant difference between the autoradiographs from subgroups $2 b$ and $2 e$ is that the radioactive deposit in the posterior wall of the femoral diaphysis is somewhat thinner in subgroup $2 e$. This is due to resorption at the endosteal surface, which is responsible for the transverse growth of the medullary cavity.

The sharp boundaries separating regions of radioactive and non-radioactive bone material are seen in the superposed autoradiographs to coincide closely with the contours of the diaphyseal cortex at the time of the dietary change-over.

\section{Plate 4}

Exp. 2. Autoradiographs from subgroups $2 c$ and $2 e$ showing the effect of the high- and low-Ca diets on femoral growth:

(I) Subgroup 2c, high-Ca diet;

(2) Subgroup 2c, low-Ca diet;

(3) Autoradiographs (I) and (2) superposed.

The femur corresponding to the high-Ca diet is longer than the other and shows a less extensive region of endosteal apposition in the distal metaphysis, particularly in the anterior wall. In (2), the growth pattern in the anterior wall of the whole diaphysis strongly suggests a reduction in the diameter of the distal half of the diaphysis by remodelling. Compared with ( $I$ ) both periosteal resorption and endosteal apposition are more pronounced in this region of the cortex and combine to produce the change in diameter.

(4) Subgroup $2 c$, high-Ca diet;

(5) Subgroup 2c, low-Ca diet.

Another pair of autoradiographs corresponding to a slightly different section plane, but showing the same effects as ( $\mathrm{I}$ ) and (2).

(6) Subgroup $2 d$, high-Ca diet;

(7) Subgroup 2d, low-Ca diet.

The femur shown in (6) is again longer than that in (7) and appears to have grown more in length during the age period 301-4I9 days. The endosteal deposit of radioactive bone material in the anterior metaphyseal wall is no longer more extensive with the low-Ca diet; a reason for this is suggested in the text (see p. 249). 


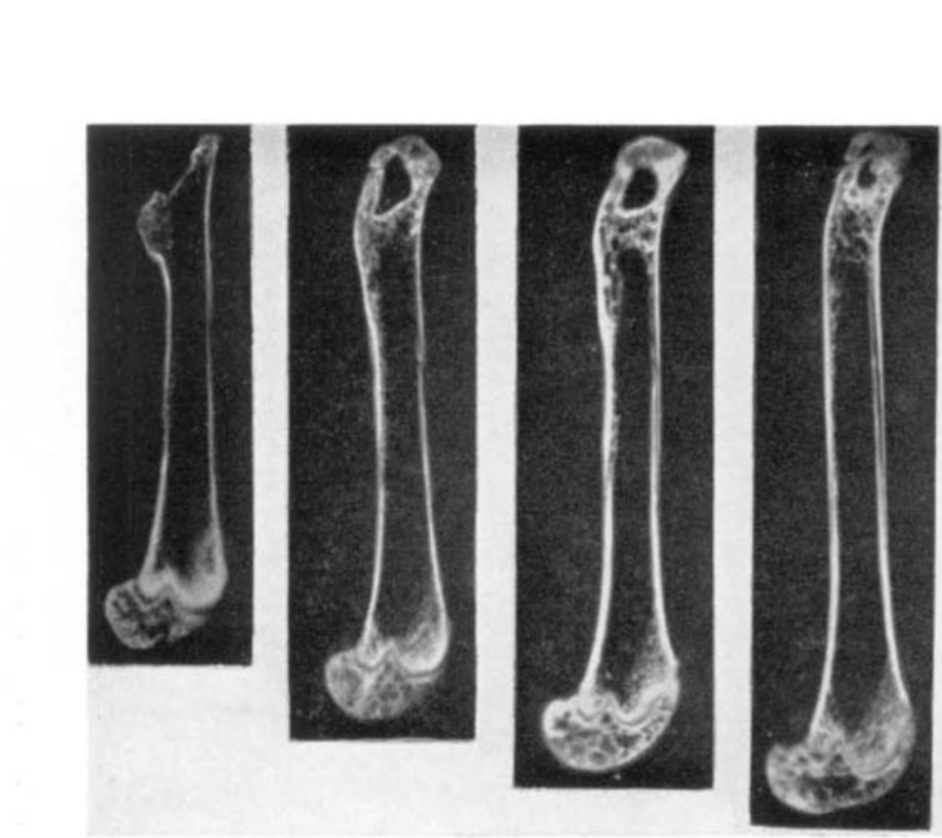

Femora

Subgroup 1a

Age of animal 47

(days)
60

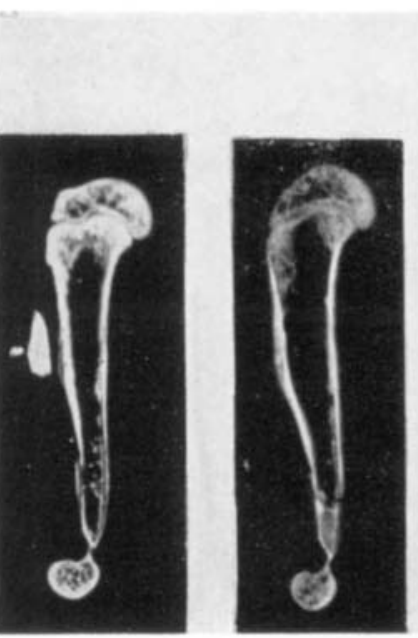

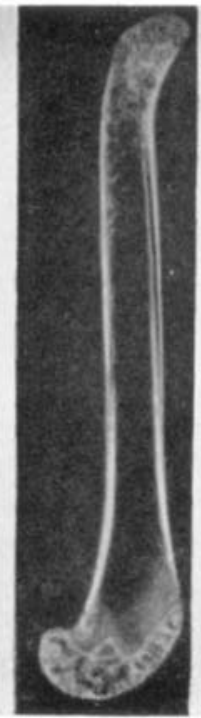

$1 f$

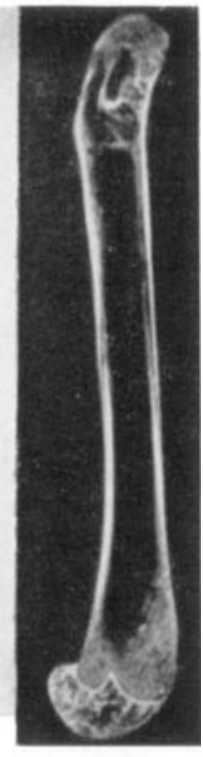

$1 h$

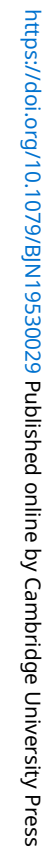
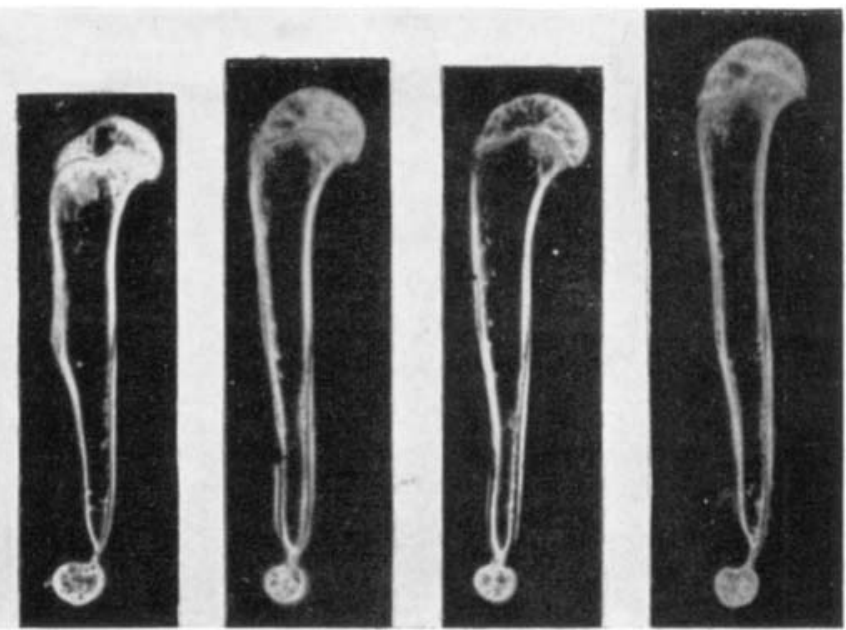

Humeri

British Fournal of Nutrition, Vol. 7, No. 3 
D. H. TOMLIN, KATHLEEN M. HENRY and S. K. KON. Autoradiographic STUDY OF GROWTH AND CALCIUM METABOLISM IN THE LONG BONES OF THE RAT
Plate 2

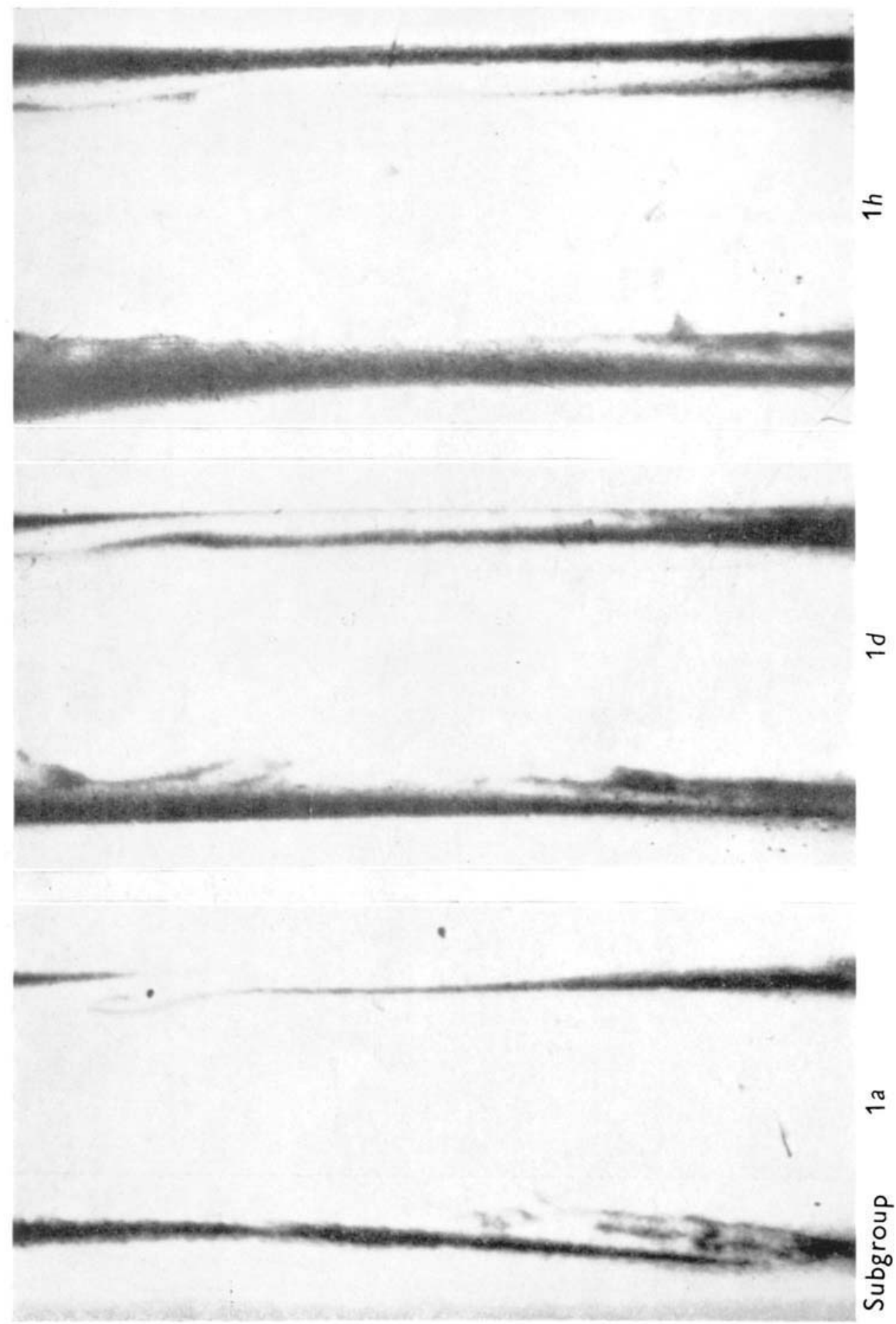

British Journal of Nutrition, Vol. 7, No. 3 
D. H. TOMLIN, KATHLEEN M. HENRY and S. K. KON. Autoradiographic STUDY OF GROWTH AND CALCIUM METABOLISM IN THE LONG BONES OF THE RAT
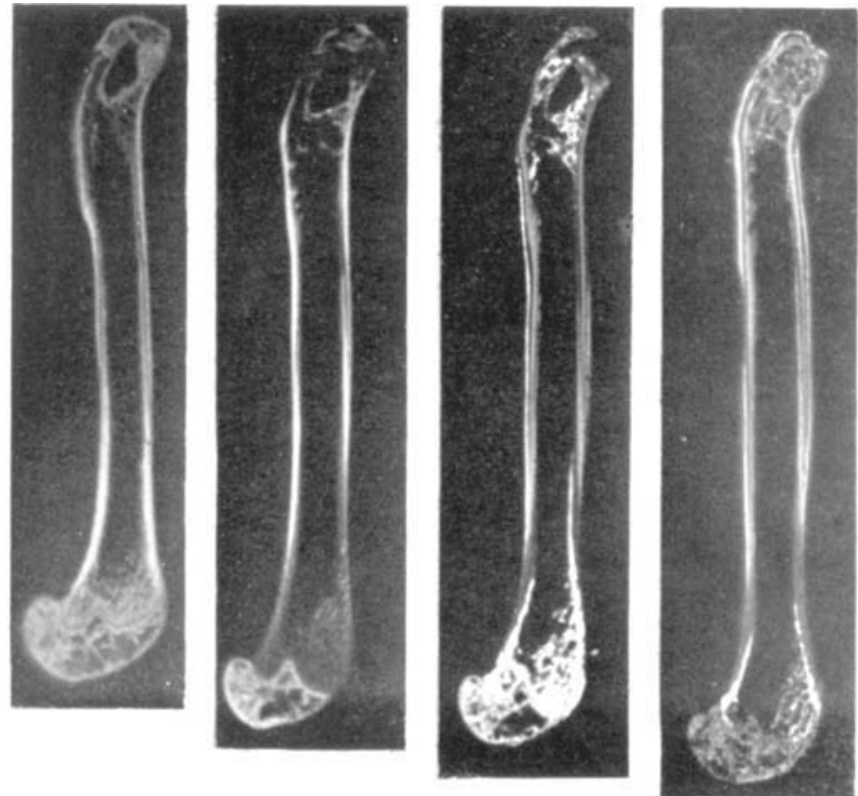

Subgroup 2a

$2 b$

218

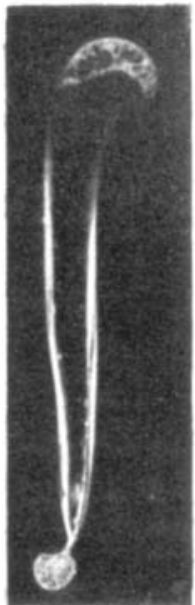

$2 c$

Femora

$2 d$

419

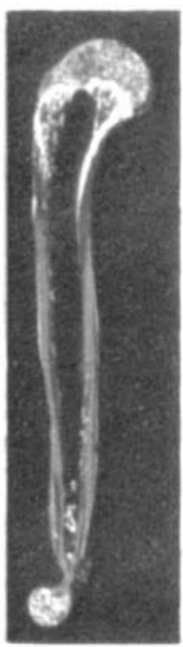

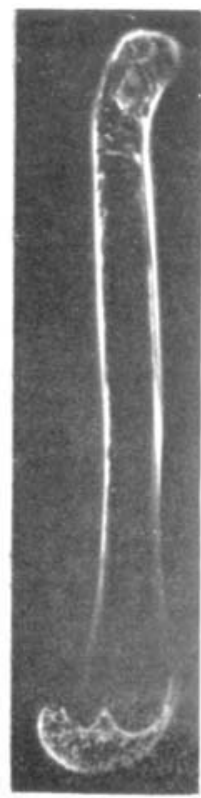

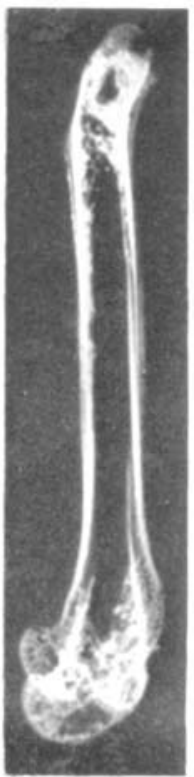

$2 e$

$2 c$ superposed on $2 a$

560
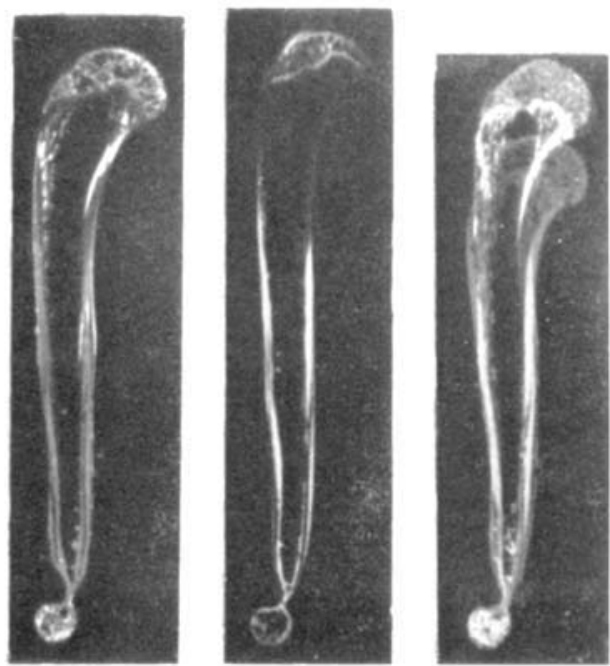

Humeri

British Yournal of Nutrition, Vol. 7, No. 3 
D. H. TOMLIN, KATHLEEN M. HENRY and S. K. KON. AUtoradiographic STUDY OF GROWTH AND CALCIUM METABOLISM IN THE LONG BONES OF THE RAT

Plate 4
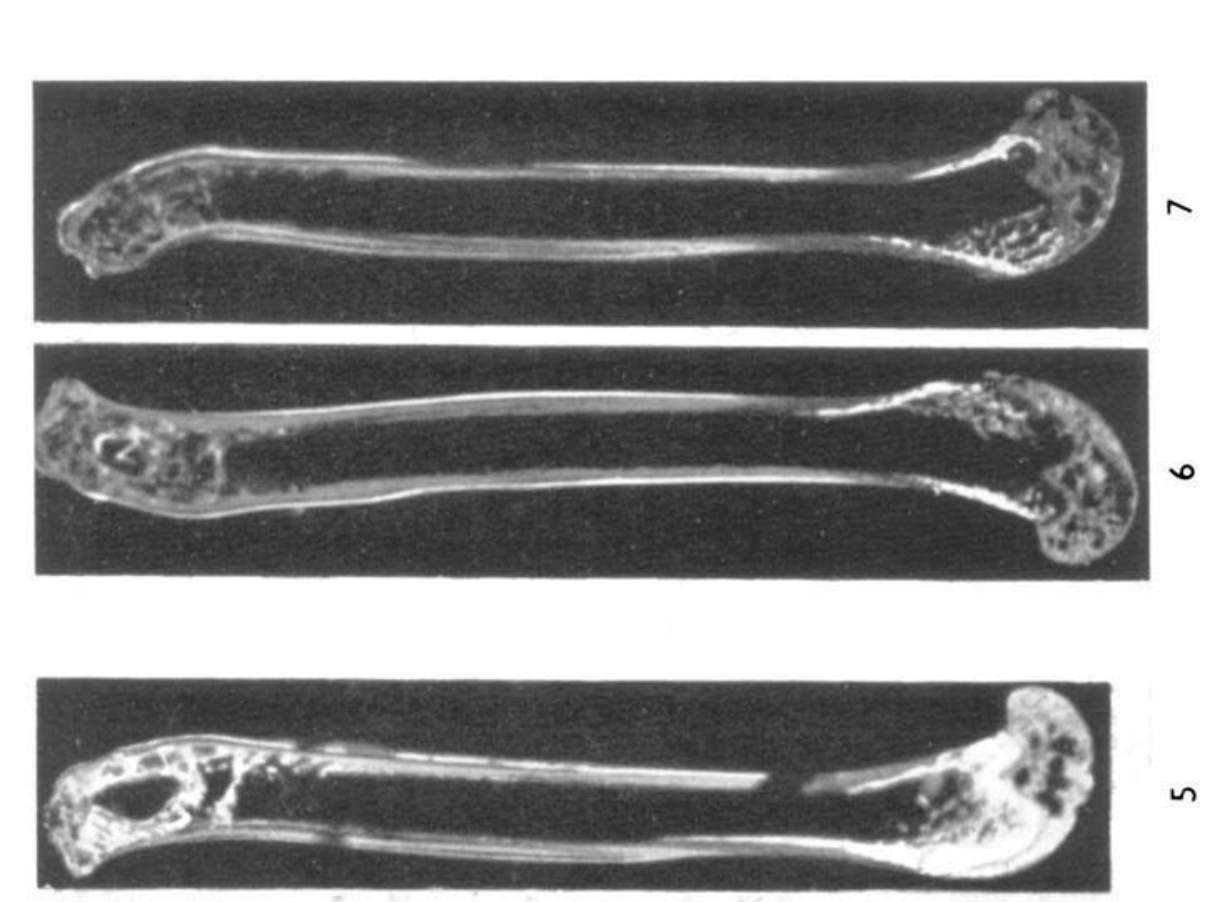

น
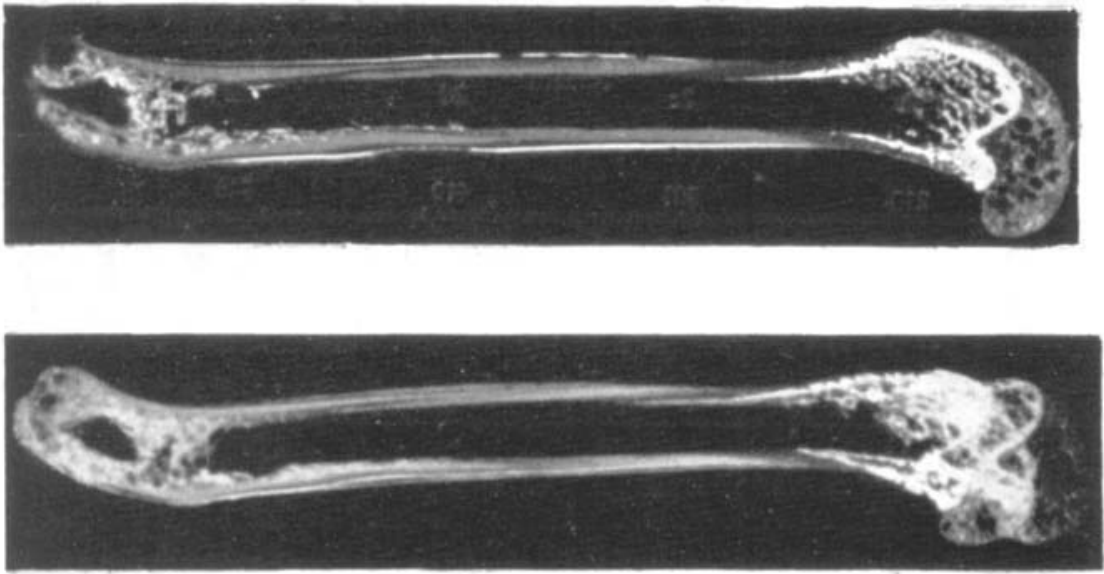

$m$

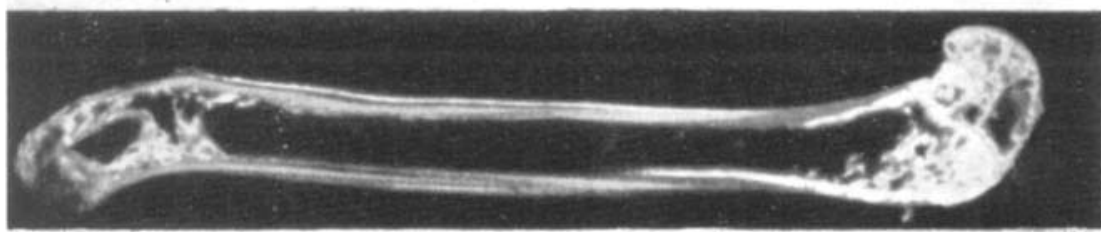

N

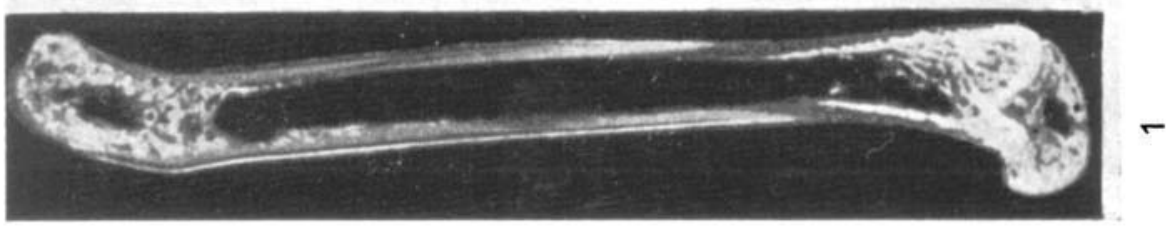

British Journal of Nutrition, Vol. 7, No. 3 